\title{
EL AÑO DEL QUIJOTE EN ESPAÑA: 1605
}

José M. ${ }^{a}$ DíEZ BorQue

Universidad Complutense de Madrid

\section{RESUMEN}

Con una extensa, variada y plural documentación se intenta reconstruir, paso a paso y con el mayor número de datos posibles, la vida literaria, artística, cultural, política, religiosa, lúdica, diaria el año de publicación de la primera parte del Quijote. En cada uno de los subapartados (vida poética, espectáculo teatral, prosa de ficción, arte, ciencia, actividad política, guerra, religión, fiesta, vida diaria, sucesos). Una minuciosa y detallada información permite acercarse, con datos ciertos, a la España en que vio la luz la primera parte del Quijote, el año en que ello se produjo.

Palabras clave: España y el «Quijote». Vida literaria, artística, cultural, política, religiosa, lúdica, diaria en 1605.

\section{ABSTRACT}

This article tries to reconstruct with a large, various and plural documentation, step by step, and with a huge number of data, the literary, artistic, cultural, politic, religious, ludic, daily life, the year in which Quijote's first edition came out.

In each one of the subparagraphs (poetic life, theatre performance, prose of fiction, art, science politic activity, war, religious, feast, daily life, events) a thorough and detail information allows to come over, with certain data, to the Spain in which the Quijote's first edition brought out.

Key words: Spain and Quijote. Literary, artistic, cultural, politic, religious, ludic, dialy life in 1605 .

\section{INTRODUCCIÓN}

Cualquier ciudadano avisado se habrá formado idea de lo que ha ocurrido en España el año en que se ha conmemorado la publicación de la primera parte del Quijote, es decir, 2005. Me tentaba preguntarme por lo que ocurría en España hace cuatrocientos años, es decir, en 1605. A ello responden las páginas que siguen, en las que hay una voluntad de reconstruir paso a paso, en la medida de lo posible, y con el mayor número de datos concretos, la vida literaria, artística, cultural; la vida política; la vida religiosa; la vida lúdica y festiva y la vida diaria. Se intenta responder a muchas preguntas pertinentes sobre la España de Cervantes y de don Qui- 
jote, exactamente en 1605, lo que significa un esfuerzo de «microhistoria», para transitar con la contundencia y certeza de datos concretos por los apasionantes caminos de vida y literatura ${ }^{1}$.

\section{VIDA LITERARIA, ARTÍSTICA, CULTURAL}

\section{Poesía y vida poética}

En poesía, aunque no aparezcan obras poéticas importantes el año en que se difunde la primera parte del Quijote, la vida poética, como en todo el Siglo de Oro, era rica y compleja, en cuanto que no sólo hay que atender - como ya nos enseñó Rodríguez Moñino ${ }^{2}$ - a lo publicado, sino a lo manuscrito, y además a la poesía mural de los pasquines poéticos, a la poesía visual de la fiesta cortesana, al mar extenso de los pliegos de cordel y, claro, al desbordante mundo de los poemas que acompañan los trabajos y los días en los ámbitos de la oralidad. Tenemos algún testimonio de poesía en la calle en el Valladolid de 1605:

Fuimos al Prado, donde cantó en extremo bien un soneto del conde de Salinas. $^{3}$

Me acerqué con el afán de oír las sentencias, discreteos y sonetos que decían los galanes cortesanos a las damas. ${ }^{4}$

[En el Prado de San Juan] hay muchas matracas de estudiantes que hacen tonos improvisados en competencia. Divididos en prosa y verso. ${ }^{5}$

Y romances se cantan en el espacio privado de la casa y público de la calle $^{6}$, a la par que se coleccionan y publican en romanceros impresos. En 1605 se publica en Valladolid la Segunda parte del romancero general y

${ }^{1}$ Me he ocupado ya de estas cuestiones en estudios míos anteriores: «Las literaturas que rodean al Quijote (1596-1605)», Don Quijote en el campus. Tesoros complutenses, ed. José María Díez Borque - José Manuel Lucía Megías, Madrid, Universidad Complutense, 2005, pp. 69-91. «1605: Vida y Literatura». Vida, literatura e imaginario en la España del Quijote. Armas y letras, ed. José María Díez Borque, Burgos, Instituto Castellano y Leonés de la Lengua, 2005, pp. 15-32. Retengo algunos datos aquí, en un conjunto sustancialmente ampliado y reelaborado.

${ }^{2}$ RODRÍGUeZ MOÑINO, Antonio, Construcción crítica y realidad histórica en la poesía de los siglos XVI y XVII, Madrid, Castalia, 1965.

${ }^{3}$ Pinheiro, Tomé, Fastiginia o fastos generales, trad. y notas N. Alonso Cortés, Valladolid, Ayuntamiento, 1973, p. 98.

${ }^{4}$ Ibidem, p. 109.

5 Ibidem, p. 180.

${ }^{6}$ Ibidem, p. 145. 
flor de diversas poesías, publicado por Luis Sánchez, y aparecen otras colecciones de romances en este año, publicadas en Lisboa, Zaragoza, etc. ${ }^{7}$

Eran frecuentes los certámenes, academias justas poéticas, poesía de encargo, poemas improvisados en esa época que ha sido calificada de «plusvalía poética». Sabemos, por ejemplo, que en un certamen de poesía latina en Salamanca el 16 de junio el premio fue de 70 reales $^{8}$.

Excepto las Flores de poetas ilustres, de Espinosa, a que me referiré más adelante, no se publican en 1605 obras poéticas importantes, aunque, como queda dicho, no suponga esto la ausencia de una rica vida poética, pero sobre la que es difícil tener datos ciertos. Cabe pensar que por fecha de nacimiento y obra publicada escribirían por entonces poetas como Rufo (n. 1547), Rey de Artieda (n. 1549), Espinel (n. 1550), Cueva (n. 1550), Virués (n. 1550), L. Leonardo de Argensola (n. 1554), Lasso de la Vega (n. 1559), Arguijo (n. 1560), Valdivieso (n. 1560), Góngora (n. 1561), B. Leonardo de Argensola (n. 1562), Lope de Vega (n. 1562), Ledesma (n.¿1562?), Medrano (n. 1570), Caro (n. 1573), Quevedo (n. 1580), y, quizá, los más jóvenes, nacidos a partir de los ochenta, como Carrillo (1582), Villamediana (1582), Jáuregui (1583), Rioja (1583), Soto (1585). Sobre muchos de ellos (Rufo, Rey de Artieda, Virués, Cueva, Argensola, Lasso, Valdivieso, Góngora, Lope, Ledesma, Jáuregui, etc.) nos ha dejado Cervantes personales valoraciones y juicios literarios en La Galatea, Viaje del Parnaso, Quijote, como he estudiado en otro lugar'.

En Zaragoza, 1605, aparece la colección poética de Rey de Artieda Discursos, epístolas y epigramas de Artemidoro, pero es mucho más importante que este mismo año se publica la Primera parte de las Flores de poetas ilustres de España (Valladolid, Luis Sánchez, 1605, hubo dos tiradas, con cambios $^{10}$ ). Es una muy interesante antología de poesía de la época con 228 poemas. Dominan los poetas antequerano-granadinos, pero los hay de fuera de Andalucía y tan importantes como Fray Luis de León, Lupercio Leonardo de Argensola, Quevedo, etc. Aunque falten poetas importantes, tiene carácter de antología de poesía de la época, «libro de oro, el mejor tesoro de la poesía castellana» (Gallardo) ${ }^{11}$, que cumple «respecto

\footnotetext{
${ }^{7}$ RodríGuez MoÑInO, Antonio, Manual bibliográfico de Cancioneros y Romanceros (Siglo XVII), Madrid, Castalia, 1977.

${ }^{8}$ Diario de un estudiante de Salamanca. La crónica inédita de Girolamo da Sommaia (1603-1607), ed. G. Haley, Salamanca, Universidad, 1977, p. 363.

9 DíEz BorQue, José María, «Las literaturas que rodean al Quijote (1596-1605)», Don Quijote en el Campus. Tesoros Complutenses, cit., pp. 69-91. Ver también SEVILLA, Florencio, Cervantes. Cultura literaria, Madrid, BNM, CEC, 1997.

${ }^{10}$ EsPinosa, Pedro, Poesías completas, ed. F. López Estrada, Madrid, Espasa Calpe, 1975, p. LIV. No he podido ver la edición de Belén Molina que anuncia la Fundación José Manuel Lara para noviembre de 2005.

${ }^{11}$ Hurtado, J. - González Palencia, A., Historia de la literatura española, Madrid, Tipografía de Archivos, 1932, p. 550.
} 
a nuestra poesía lírica de la Edad de Oro una misión parecida a la de los Cancioneros respecto al reinado de los Reyes Católicos y anteriores» ${ }^{12}$. Por ello debió de enojar a Cervantes el que no se incluyeran poemas suyos, pues sabemos su obsesión por ser reconocido como poeta, y debía de estar dolido, además, por lo que había escrito Lope sobre él un año antes en agosto (según Astrana Marín sería en diciembre de $1605^{13}$ ): «de poetas no digo buen siglo es éste; muchos en ciernes para el año que viene, pero ninguno hay tan malo como Cervantes ${ }^{14}$.

\section{Teatro y espectáculo teatral}

El teatro es el gran espectáculo para todos en la España del Siglo de Oro, sin equivalente ni competencia de otras manifestaciones lúdicas. En cuanto a la literatura dramática —antes de ocuparme de la organización del espectáculo- hay que subrayar que en el año que nos ocupa el modelo lopesco ya está afianzado y es seguido por los dramaturgos que estrenan y representan en los corrales de comedias. Lope escribe, entre otras, La noche toledana ${ }^{15}$. Aparece Parte I de Comedias de Lope de Vega en Lisboa (J. Rodríguez - E. López), Valencia (G. Leget - F. Miguel), Valladolid (J. de Bustillo, A. Pérez, A. Coello) ${ }^{16}$. Por otra parte, estaría activa la escuela valenciana con Guillén de Castro, Tárrega, Boyl, Aguilar, y dramaturgos como Tirso de Molina, Vélez de Guevara, Ruiz de Alarcón, Amescua..., tendrían entre 25 y 30 años. Pero, obviamente, no puedo entrar aquí en el estudio pormenorizado de todo esto.

El genial creador de la novela moderna no supo o no quiso entender y seguir al creador del teatro moderno. Baste volver a recordar el tan conocido y citado pasaje del Quijote:

$\mathrm{Y}$ no tienen la culpa desto los poetas que las componen, porque algunos hay dellos que conocen muy bien en lo que yerran, y saben extremadamente lo que deben hacer; pero como las comedias se han hecho mercadería vendible, dicen y dicen verdad, que los representantes no se las comprarían si no fuesen de aquel jaez; y así, el poeta procura acomodarse con lo que el representante que le ha de pagar su obra le pide. Y que esto sea verdad véase por

12 DíEZ-Echarri, E. - Roca Franquesa, J. M., Historia general de la literatura española e hispanoamericana, Madrid, Aguilar, 1968, p. 424.

13 ASTRAna, Luis, Vida ejemplar y heroica de Miguel de Cervantes Saavedra (...), Madrid, 1948-1958, VI-I, pp. 40-146.

${ }^{14}$ Entrambasaguas, Joaquín de, Vivir y crear de Lope de Vega, Madrid, Árbor, 1946, pp. 238-239.

${ }^{15}$ Morley, S. E. - Bruerton, C., Cronología de las comedias de Lope de Vega, Madrid, Gredos, 1968, p. 85.

${ }^{16}$ GRUPO PROLOPE, «El Lope de 1604», Lope en 1604, Barcelona-Lleida, Universidad-Milenio, 2004, p. 15. 
muchas e infinitas comedias que ha compuesto un felicísimo ingenio destos reinos, con tanta gala, con tanto donaire, con tan elegante verso, con tan buenas razones, con tan graves sentencias $\mathrm{y}$, finalmente, tan llenas de elocución y alteza de estilo, que tiene lleno el mundo de su fama; y, por querer acomodarse al gusto de los representantes, no han llegado todas, como han llegado algunas, al punto de perfección que requieren. Otros las componen tan sin mirar lo que hacen que después de representadas tienen necesidad los recitantes de huirse y ausentarse, temerosos de ser castigados, como lo han sido muchas veces, por haber representado cosas en perjuicio de algunos reyes y en deshonra de algunos linajes ${ }^{17}$.

Continúa insistiendo 10 años después en el «Prólogo»a Ocho Comedias y ocho entremeses:

Avasalló y puso debajo de su jurisdicción a todos los farsantes; llenó el mundo de comedias propias, felices y bien razonadas, y tantas que pasan de diez mil pliegos los que tiene escritos, y todas, que es una de las mayores cosas que pueden decirse, las ha visto representar o oído decir por lo menos que se han representado; y si algunos, que hay muchos, han querido entrar a la parte y gloria de sus trabajos, todos juntos no llegan en lo que han escrito a la mitad de lo que él solo ${ }^{18}$.

Pero las relaciones Cervantes-Lope constituyen uno de los más apasionantes problemas de la historia literaria del Siglo de Oro, que implica cuestiones complejas de teoría e historia teatrales, poética del gusto, teoría de la recepción, concepto de vulgo, aristotelismo, antiguo / moderno, etc., etc., en las que, en absoluto, puedo entrar aquí, pero de las que me he ocupado en varios estudios ${ }^{19}$, con la referencia de la bibliografía pertinente (Canavaggio, Chaytor, del Arco, Wardropper, Zimic, Granja, etc.)

El año que ve la luz la primera parte del Quijote el teatro, como dije, es ya el espectáculo por excelencia, afianzado en España y en el Nuevo Mundo, con una estructura profesional y organización económica que lo convierten en la gran máquina del ocio y de la pública diversión. Dispone-

${ }^{17}$ Cervantes, Miguel de, Don Quijote, ed. M. de Riquer, Barcelona, Planeta, 1975, p. 525 .

${ }^{18}$ Cervantes, Miguel de, «Prólogo». Ocho comedias, ed. F. Sevilla, A. Rey, Barcelona, Planeta, 1987, p. 10.

19 DíEZ Borque, José M. ${ }^{\text {a }}$, «Lope para el vulgo. Niveles de significación», Teoría y realidad en el teatro español del siglo XVII. La influencia italiana, ed. F. Ramos, Roma, IEC, 1981, pp. 302 y ss.

DíEZ BORQue, José M. ${ }^{a}$, «Poética de la recepción: nueva teoría para un nuevo espectáculo, el primer teatro popular», Congrés Internacional de Teatre a Catalunya, ed. J. Coca y L. Coneza, Barcelona, I. de Teatre, 1987, pp. 203-231.

DíEz Borque, José M. ${ }^{a}$, «La historia del teatro según Cervantes», Cervantes y la puesta en escena de la sociedad de su tiempo, ed. C. Poupeney, A. Hermenegildo, C. Oliva, Murcia, Universidad, 1999, pp. 17-53.

DíEZ BORQue, José M. ${ }^{a}$, «Cervantes y la vida teatral del Siglo de Oro», Teatro (prensa). Además los citados en nota 1 y en nota siguiente. 
mos de numerosos estudios de carácter «local» que van permitiendo formar una idea de lo que ocurría «teatralmente» en diversas ciudades y pueblos de la España del XVII, en el camino hacia una síntesis necesaria. Me limitaré aquí a ofrecer unas calas sintomáticas sobre el espectáculo teatral en algunas ciudades españolas el año de gracia de $1605^{20}$, dejando para el final el teatro en la corte abandonada (Madrid) y en la nueva corte (Valladolid).

Para León, sabemos que se pagan 2850 reales al autor de comedias Vergara, para representar las fiestas de la Asunción, procedente de Valladolid, y que se conciertan pagos para representar comedias por el nacimiento del príncipe Felipe (además de toros y música ${ }^{21}$ ). Hay datos sobre maestros de danzas dramáticas en Ávila, donde es posible que estuviera a finales de 1605 el autor de comedias Diego López de Alcaraz y se representaran autos de Navidad con 550 reales para el hospita ${ }^{22}$. De Córdoba tenemos datos sobre contratos y funcionamiento del Corral de Comedias y la curiosa noticia de la expulsión de una compañía teatral ${ }^{23}$. Los contratos de actores, con informaciones sobre sueldos, obligaciones, estipulaciones, conservados muestran la actividad teatral en ciudades y pueblos como Badajoz ${ }^{24}$, Logroño ${ }^{25}$, Alfaro ${ }^{26}$, lo mismo que para Burgos descubre una amplísima documentación obras en el corral de comedias, localidades, problemas con el corregidor y la utilización gratuita de aposentos, etc ${ }^{27}$. De Oviedo tenemos noticia de tablados en la plaza, comedias, letras a lo divino, bailes, etc. ${ }^{28}$.

Más adelante me referiré a la celebración de la fiesta del Corpus con procesiones, danzas, celebraciones diversas. La representación de autos sacramentales estaba ya generalizada. Basten como testimonio los 1800 rea-

${ }^{20} \mathrm{Me}$ ocuparé con detalle de todo esto en el estudio que preparo «El teatro en España el año del Quijote: 1605». Son numerosas ya las investigaciones sobre el teatro «local» en distintas ciudades y pueblos de España y las aportaciones documentales. Recojo algunos aquí, pero remito a mi trabajo en preparación para la referencia y valoración de las aportaciones de Pérez Pastor, Díaz de Escovar, Juliá, del Arco, Barceló, Lamarca, Merimée, Giménez Soler, etc., y otros de nuestros días.

${ }^{21}$ VIFORCOS, M. ${ }^{a}$ Isabel, El teatro en los festejos leoneses del siglo XVII, León, Universidad, 1994, pp. 193; 216-217.

${ }^{22}$ BERnAldo DE QuiRós, José A., Teatro y actividades afines en la ciudad de Ávila (...), Ávila Diputación, 1997, pp. 96; 61; 52.

${ }^{23}$ García GómEZ, Ángel M. ${ }^{a}$, Actividad teatral en Córdoba y arrendamientos de la casa de las comedias: 1602-1737. Estudio y documentos, London - Córdoba, TamesisDiputación, 1999, pp. 140-143.

${ }^{24}$ Marcos Álvarez, Fernando, Teatros y vida teatral en Badajoz: 1601-1700. Estudio y documentación, London, Tamesis, 1997, pp. 118-119.

${ }_{25}$ Domínguez Matito, Francisco, El teatro en la Rioja 1580-1808, Logroño, Universidad de La Rioja, 1998, pp. 267-269.

${ }^{26}$ Ibidem, p. 267.

27 Miguel Gallo, Ignacio Javier de, El teatro en Burgos (1550-1752) (...), Burgos, Ayuntamiento, 1994, pp. 193 y ss.

${ }^{28}$ García Valdés, Celsa Carmen, El teatro en Oviedo (1498-1700) (...), Oviedo, Instituto de Estudios Asturianos - Universidad de Oviedo, 1983, p. 233. 
les que se pagan en Badajoz para ello ${ }^{29}$, la noticia de que los representó el autor de comedias Antonio de Villegas en Sevilla ${ }^{30}$, con el dato concreto de que se puso en escena La privanza del hombre, de Lope de Vega, y la tragicomedia El cordobés valeroso ${ }^{31}$.

Pero creo que la información más interesante y sugestiva sobre el espectáculo teatral el año de publicación de la primera parte del Quijote es la que proporciona el estudiante salmantino Girolamo da Sommaia al darnos la relación de obras estrenadas día a día y, en ocasiones, el autor de comedias, lugar, etc., lo que retomaré en mi estudio citado ${ }^{32}$, intentando identificar las obras. A pesar de lo enojoso de la nómina merece la pena retener la relación de obras representadas: El galán secreto (28-V, Vergara), El desdichado dichoso (30-V, Vergara), El bosque de amor (1-VI), El último godo (2-VI). El desposorio encubierto (3-VI), Segunda parte del Príncipe Transilvana (5-VI), El gallardo veneciano (13-IX), Clérigo bandolero, intermedio de la Isla de la Ciaccona (13-IX), La cantante bofeteada (15-IX), La prudente fortaleza (17-IX), El cerco de Canarias (17-IX y 18IX), Los descasados de Valencia (21-IX), La esclava de su padre y Los Tabelliones de Portugal (21-IX), Vida de Santa Catalina de Siena (22-IX), La católica paz entre España y Francia (24-IX), El bienquisto por sus obras (25-IX y antes el 23-IX), Los enredos premiados (27-IX, Riquelme), Los reinos divididos (28-IX, Alcaraz), El primer conde de Flandes (29-IX), Los monteros de Espinosa (30-IX), La crueldad piadosa (1-X), La flor de lis de Francia (2-X), El origen de la cruz (3-X), El peregrino disfrazado (4$\mathrm{X})$, La pérdida honrosa. El sitio de Rodas (5-X), Los amantes enemigos (6-X), El genovés venturoso (7-X), El humilde venturoso (8-X), La presa de Rodas (9-X), Las esquinas (sic) de Portugal (10-X), El esclavo del cielo (11-X), El pobre honrado (12-X), El colmenar (13-X), El duque de Alba en París (14-X), La nueva perseguida (17-X), La defensa de Toledo (18$\mathrm{X})$, El veneciano piadoso (7-XII), El remedio en la desdicha (11-XII), Los hechos de García de Paredes (12-XII), El corsario de su dama (13-XII, Ríos), Las reinas encontradas en día de (...) (17-XII), El trato de Salamanca (18-XII), El disparate de amor (21-XII), El soldado a mercé (24-XII), El desengaño dichoso (25-XII), La cartuja (26-XII), La noche toledana (27XII), Los cautivos de Argel (29-XII), El cerco de Lisboa (31-XII).

Nos proporciona, además, el estudiante salmantino, gran aficionado al teatro, algunos datos sobre vida teatral, como que se copiaban comedias; que costaba, en septiembre de 1605, dos reales la entrada; que el 20 de septiembre y 14 de octubre no se representó por la lluvia; que en septiem-

29 Marcos Álvarez, Fernando, Op. cit., p. 118.

30 Sentaurens, Jean, Seville et le théâtre(...), Lille, Universidad, 1984, II, p. 1274.

31 SÁnchez-Arjona, José, Anales del teatro en Sevilla, ed. P. Bolaños - M. de los Reyes, Sevilla, Ayuntamiento, 1994, pp. 122-124.

32 DÍEZ BORQUE, «El teatro, cit.». 
bre se representaron las fiestas del Corpus; que se daban comedias en casas nobles, como la de los Anaya, con asistencia del Alcalde de Corte (2 de octubre); que un aposento costaba 6 reales en octubre, etc ${ }^{33}$.

En la abandonada Corte de Madrid el teatro languidece. Este año de 1605 se pregona el arriendo de los $\operatorname{corrales}^{34}$. Hacía 22 años que funcionaba el del Príncipe y 26 el de la Cruz. En cambio, en la nueva Corte de Valladolid parece que había una vida teatral y espectacular intensas. En marzo se había construido una sala para saraos en el palacio del rey ${ }^{35}$. En julio estaba representando Riquelme entremés y comedia de portugueses ${ }^{36}$, y los reyes se entretenían en «ver comedias» en Lerma, representadas por Ríos y su compañía ${ }^{37}$. Para el Corpus se pagaron 1000 ducados para las representaciones $^{38}$. Había también teatro en conventos representado por las monjas ${ }^{39}$. Pero habrá que ahondar en el estudio del teatro en la corte vallisoletana ${ }^{40}$.

\section{Prosa de ficción}

No voy a considerar diversos géneros literarios en prosa (tratados políticos, filosóficos, religiosos, historia... etc.) y tampoco voy a entrar en el debate sobre su literariedad. Me limitaré a la prosa de ficción que, por razones obvias, interesa especialmente aquí, para enmarcar la genial creación cervantina y subrayar que aunque el Quijote se produzca, como diré después, en el marco de un género tan afianzado cual era el de la novela de caballerías $^{41}$, lo desborda, con el carácter de obra atípica y singular, sin que nada en el entorno hiciera previsible su aparición. Por eso su genialidad, repercusión universal y condición de creadora de la novela moderna ${ }^{42}$.

${ }^{33}$ Diario de un estudiante, cit. La referencia es la fecha que se da para los datos de vida teatral: pp. 399; 403; 405; 408; 413.

34 VAREY, J. E. - Shergold, N. D., Los arriendos de los corrales de comedias de Madrid: 1587-1719. Estudio y documentos, London, Tamesis, 1987, p. 69.

${ }^{35}$ CABRera, Luis, Relación de las cosas sucedidas en la corte de España desde 1599 hasta 1614, prefacio de R. García Cárcel, Salamanca, Junta de Castilla y León, 1997, p. 238.

${ }^{36}$ Pinheiro, Tomé, Op. cit., p. 226.

37 CABrera, L., Op. cit., p. 254.

${ }^{38}$ PinHeiro, Tomé, Op. cit., p. 122.

${ }^{39}$ Ibidem, p. 240

${ }^{40}$ No he podido ver el estudio de Alonso Cortés, Narciso, El teatro en Valladolid, Madrid, Tipografía de Archivos, 1923.

${ }^{41}$ LuCía Megías, José Manuel, «Libros de caballerías castellanas: un género recuperado», Letras, 50-51 (julio 2004-junio 2005), pp. 203-234.

${ }^{42}$ Naturalmente hay numerosos estudios pertinentes, en que no puedo entrar aquí, pero remito al reciente de Javier BLASCO, Cervantes raro inventor, Alcalá de Henares, Centro de Estudios Cervantinos, 2005 
No es cuestión pertinente aquí la de la posible difusión del Quijote a finales de 1604, ni la difusión fuera de España, ni siquiera el éxito inmediato en ésta. Baste con retener lo que escribe Chartier:

Es muy posible que entre 1605 y 1615 salieran al mercado doce mil ejemplares, ya que en esos años se publicaron nueve ediciones de la novela: tres en Madrid (dos en 1605, una en 1608); dos en Lisboa (ambas en 1605); una en Valencia en 1605; y una en Milán y dos en Bruselas (y no Amberes) en 1607 y $1611^{43}$.

Tenemos datos curiosos, además, de la circulación de la obra a finales de 1605 por préstamo de unos a otros, incluso sin encuadernar ${ }^{44}$.

Lo que interesa es enmarcar el Quijote en la prosa de ficción en 1605, para lo que retendré, con adiciones, lo que escribí en otra ocasión ${ }^{45}$.

En 1605 aparece La pícara Justina bajo el nombre de López de Úbeda (no hace al caso entrar aquí en los problemas de autoría), de protagonista femenino, como después en La hija de Celestina de Salas Barbadillo; La niña de los embustes, Teresa de Manzanares, de Castillo Solórzano, etc. Pero la crítica coincide en señalar el escaso interés de esta obra como novela picaresca y más como «documento lingüístico y tratado de moral». Tampoco parece que fuera muy positiva la opinión de Cervantes sobre esta obra:

$$
\begin{aligned}
& \text { Haldeando venía y trasudando } \\
& \text { el autor de La pícara Justina, } \\
& \text { capellán lego del contrario bando. } \\
& \text { Y cual si fuera de una culebrina, } \\
& \text { disparó de sus manos su librazo, } \\
& \text { que fue de nuestro campo la ruina }{ }^{46} \text {. }
\end{aligned}
$$

Más importante es para el género de la picaresca el que en 1603 Quevedo pudiera redactar El Buscón, y que en 1604 apareciera la segunda parte del Guzmán de Alfarache, obra de éxito editorial, que, según algunos estudiosos, querría ser emulada con una nueva forma de libro de caballerías como el Quijote.

Anteriores al momento que nos ocupa son los autores de obras importantes de otros géneros narrativos pertinentes: así Montemayor, Gil Polo, Gálvez de Montalvo, en la pastoril (aunque Lope nos dará en 1598 La Arcadia); Villegas, Núñez de Reinoso, Pérez de Hita en la llamada «nove-

${ }^{43}$ ChARTIER, Roger, «La Europa castellana durante el tiempo del Quijote», España en tiempos del Quijote, ed. Antonio Feros, Juan Gelabert, Madrid, Taurus, 2004, p. 130. Vid. RICO, Francisco, "'Don Quijote": Madrid, 1604, en prensa», El Quijote. Biografía de un libro, com. Mercedes Dexeus, Madrid, Biblioteca Nacional, 2005, pp. 51-75.

${ }^{44}$ Diario de un estudiante, cit., pp. 428, 434, 61.

45 Díez Borque, José María, «1605: Vida», cit., pp. 27-29.

${ }^{46}$ Cervantes, Miguel de, Viaje del Parnaso, ed. V. Gaos, Madrid, Castalia, 1974, vv. 220-225; pp.155-160. 
la morisca»; Núñez de Reinoso, Contreras en la mal llamada «novela bizantina», de aventuras (aunque todavía en 1616 aparece Trabajos de Persiles y Sigismunda, de Cervantes).

Aunque el Quijote sea mucho más que un libro de caballerías y su intención vaya mucho más lejos de destruir un género, es cierto que nuestro peculiar caballero andante construye su mundo con el modelo caballeresco, al que hay continuadas alusiones que nos descubren a Cervantes como un gran conocedor del género. Sería fundamental conocer con el mayor detalle el peso de la caballeresca en los años en que aparece la primera parte del Quijote. Repasando las aportaciones de diversos estudiosos (Riquer, Chevalier, Lucía... etc.) parece que los años que van de 1521 a 1560 son los de mayor esplendor editorial del género; y cotejando la bibliografía de Eisenberg-Pina ${ }^{46}$ bis observamos que el bloque de ediciones más tardías se sitúa en la década de los ochenta, aunque recojan también aisladas ediciones posteriores: Amadis de Grecia (1596), Primaleón (1598), Policisne de Boecia (1602), y hasta en 1617 de El caballero de Febo. Está además el curioso dato de que Cervantes pudiera haber escrito un libro de caballerías, Bernardo del Carpio (Eisenberg-Pina, vid. Bernardo [del Carpio]), que, de conservarse, aportaría luz a la interpretación del Quijote. Sin entrar aquí en mayores disquisiciones, parece de recibo la afirmación de Canavaggio:

En el año de gracia de 1605, los Amadises y otros Palmerines son libros que todavía se leen, pero ya no son obras de moda [...] la novela de caballerías alcanza un punto culminante durante el reinado de Carlos $\mathrm{V}$, para decrecer lentamente en la segunda mitad del siglo $\mathrm{XVI}^{47}$.

Decadencia que el mencionado investigador atribuye no sólo a la hostilidad y ataques de moralistas, autoridades civiles y religiosas, sino al cambio de gustos porque «no pueden ya ofrecerles la representación idealizada del mundo en que habrían querido vivir» ${ }^{48}$. Pero el problema es complejo porque habría que atender también, como apuntan Alvar y Lucía Megías ${ }^{49}$, a otras formas de difusión (oral, manuscrito, pliego de cordel...), y también a la permanencia de los ideales de la caballería en otros géneros literarios.

Recordando el capítulo VI de la primera parte del Quijote, con el fa-

46 bis RIQUER, Martín de, «Cervantes y la caballeresca», Suma cervantina, ed. J. B. Avalle Arce - E. C. Riley, London, Tamesis, 1973, pp. 284-285 y nota 15.

Chevalier, Máxime, «El público de las novelas de caballerías», Lecturas y lectores en la España de los siglos XVI y XVII, Madrid, Turner, 1976.

Lucía Megías, José Manuel, Op. cit. Eisenberg, Daniel - Marín PinA, M. ${ }^{a}$ del Carmen, Bibliografía de los libros de caballerías castellanos, Zaragoza, Prensas Universitarias, 2000.

${ }^{47}$ Canavaggio, Jean, Cervantes, Madrid, Espasa Calpe, 1987, p. 177.

48 Ibidem, p. 117.

49 Alvar, Carlos, Lucía, J. M. (eds.), Libros de caballerías castellanos: una antología, Barcelona, Debolsillo, 2004. 
moso escrutinio de la biblioteca, lo que necesitamos es una investigación monográfica sobre las expectativas de recepción de la literatura caballeresca en los años en que ve la luz la primera parte del Quijote; sobre los alcances y sentido de éste dentro del género de los libros de caballerías y, naturalmente, sobre las distintas formas de presencia y permanencia del género, como ha estudiado Lucía Megías ${ }^{50}$.

Respecto a la vida literaria diré que había cuatro imprentas en Madrid en 1605 (en 1601 había 6), mientras que en Valladolid «durante la capitalidad vallisoletana (...) además de las cinco imprentas existentes se instalaron en la ciudad del Pisuerga otras cuatro». En Barcelona y Sevilla eran cinco, en Zaragoza, 4; en Valencia, 2..., ${ }^{51}$. Costaba 12 reales y medio la resma de papel de imprimir de Nuestra Señora del Paular (para la segunda edición del Quijote de 1605) y menos de 10 reales en Barcelona ${ }^{52}$ Pero para entender el mundo editorial y de comercio del libro hay que tener presente no sólo que se prestaban las obras, sino que, a veces, se copiaban, tanto las de menor alcance y volumen, así gacetas y relaciones ${ }^{53}$, como las literarias, como, por ejemplo, los Sueños de Quevedo ${ }^{54}$. Tenemos testimonios del préstamo de comedias de Lope, Sueños de Quevedo, Libro de la pícara, Epicteto, Galateo español, Refranes, Romancero, Fiesta de Carnestolendas, además de relaciones, cartas, gacetas, etc. ${ }^{55}$

\section{Arte}

Estarían activos en 1605, entre otros, los escultores Juan Martínez Montañés (1568-1649), Juan de Mena (1583-1627), y de este año es el Cristo del Pardo, de Gregorio Hernández y San Pedro, de Diego de Astor ${ }^{56}$. De 1605 es el lienzo El martirio de Santa Úrsula, de Pantoja ${ }^{57}$. De entre 1600 y 1605 podrían ser los lienzos Un caballero y Caballero joven de el Greco $^{58}$; de entre 1602 y 1605, Antonio de Covarrubias de el Greco y de entre 1603 y 1605 , Natividad, del mismo pintor $^{59}$. Rubens estuvo en Madrid en 1603 y su Juicio de París y Retrato del duque de Lerma no serían

\footnotetext{
${ }^{50} \mathrm{Vid}$. nota 41.

${ }^{51}$ Burgos, Javier, «La imprenta de Barcelona en el tiempo del Quijote», El Quijote y Barcelona, ed. C. Riera, Barcelona, Ajuntament - Lunwerg, 2005, p. 95.

52 Ibidem, p. 100.

${ }_{53}$ Diario de un estudiante, cit., pp. 336-349; 370-371.

${ }^{54}$ Ibidem, p. 341.

${ }^{55}$ Ibidem, passim.

56 PORTús PÉREZ, Javier (Com.), El arte en la España del Quijote, Ciudad Real, EPDQ - SECC, 2005, p. 83.

57 Ibidem, p. 43.

58 AA. VV., Museo del Prado. Catálogo de las pinturas, Madrid, M.E. y C., 1996, p. 169.

59 Portús PÉreZ, Javier, Op. cit., pp. 108; 162.
} 
posteriores a 1605. Podrían estar activos el año en que se difunde la primera parte del Quijote los pintores: Juan Pantoja (1533-1608), Luis de Carvajal (1534-1607), Greco (1541-1614), Juan Sánchez Cotán (1560-1627), Francisco Pacheco (1564-1644), Bartolomé González (1564-1627), Francisco Ribalta (1565-1628), Eugenio Cajes (1574-1634), Vicente Carducho (1576-1638), Pedro Orrente (1580-1643), Juan Bautista Mayno (1578-1649), Antonio de Lanchares (1586-1630), Rodrigo de Villandrando (i-1623) y Ribera (1591-1652) ${ }^{60}$. Velázquez tenía seis años, y el 17 de marzo de este año bautizan a Pedro de Camprubín, pintor de bodegones, en Almagro ${ }^{61}$. Por otra parte, podrían estar activos grabadores como Pedro Perret (c.15551625), Cornelio Boel (c.1580-1621), Francisco Heylan (1584-1650) y quizá Juan de Roelas (c.1588-1625) y Diego de Astor (i-1650) ${ }^{62}$.

De estas fechas son libros importantes para la historia del arte como el de Fray José de Sigüenza en que describe el monasterio de El Escorial, o el Tratado de Arte de Prado-Villalpando (Roma, 1596-1605) ${ }^{63}$.

\section{Enseñanza, ciencia, técnica}

En el ámbito de la enseñanza en 1605 mientras que en un colegio como el de Villagarcía de Campos «no se enseñan más que las reglas de la Gramática y los fundamentos de la lengua latina» a unos seiscientos estudiantes $^{64}$, en universidades como la de Baeza se enseña Gramática, Arte, Teología a 251 estudiantes. Éstas y otras disciplinas a 183 en la de Osuna, a 215 en la de Santa María de Jesús ${ }^{65}$ y en Salamanca, 1605-1606, habría 4983 estudiantes $^{66}$. Por otra parte, los estudiantes participaban activamente en las votaciones de las oposiciones a cátedra, que vivían con intensa preocupación, como muestra las detalladas informaciones que nos proporciona da Sommaia para la Universidad de Salamanca en $1605^{67}$. Las ceremonias de toma de posesión de los rectores tenían gran solemnidad y aparatosidad, como, por ejemplo, la del Rector de la Universidad de Salamanca el 11 de noviembre de $1605^{68}$.

\footnotetext{
${ }^{60}$ Ibidem, passim.

${ }^{61}$ Herrera Maldonado, Enrique, «El Arte en La Mancha en tiempos de don Quijote», La monarquía hispánica en tiempos del Quijote, ed. Porfirio Sanz Camañes, Madrid, UCLM-Silex, 2005, p. 392.

${ }^{62}$ Portús PÉrez, Javier, Op. cit.

${ }^{63}$ Ibidem, pp. 308; 304.

${ }^{64}$ Treswell, Robert, A Relation (...), Londres, 1605 en Patricia Shaw Fairman, España vista por los ingleses del siglo XVII, Madrid, SGEL, 1981, p. 99.

${ }^{65}$ Kagan, Richard L., Universalidad y sociedad en la España moderna, Madrid, Tecnos, 1981, pp. 299-301.

${ }^{66}$ Ibidem, p. 283.

${ }^{67}$ Diario de un estudiante, cit. passim.

${ }^{68}$ Ibidem, pp. 425 y ss.
} 
En el campo de las publicaciones científicas y técnicas cabe destacar que este año se publican varias obras importantes de Medicina ${ }^{69}$. Por otra parte, se estarían preparando el Atlas de Mercátor, que aparece en $1606^{70}$ (el año 1605 se había publicado el mapa de España en Nova Regni Hispaniae $^{71}$ ) y el Regimiento de Navegación de García de Céspedes, que aparece el mismo año ${ }^{72}$. Y en 1605 muere Aldrovando autor de una historia ilustrada de los animales ${ }^{73}$.

Varios son los avances e innovaciones técnicas el año de la publicación del Quijote. En 1605, 20 de junio, se le concede patente a Ayanz para su invento de «un equipo de buceo con renovación permanente del aire» ${ }^{74}$, y por entonces debía de estar en Valladolid el ingeniero Constantino Cabezudo para estudiar la navegabilidad de sus ríos ${ }^{75}$. Ese mismo año muere en Inglaterra Pedro de Zubiaurre que, entre 1603-1604, había instalado en el río Pisuerga, en Valladolid, una bomba para elevar el agua ${ }^{76}$. Cristóbal de Rojas enseña fortificación en la Academia de Matemáticas ${ }^{77}$.

\section{VIDA POLÍTICA}

\section{Corte ausente (Madrid). Corte presente (Valladolid)}

La Corte se había trasladado en 1601 de Madrid a Valladolid y allí sigue cuando se publica la primera parte del Quijote. Valladolid florece, pero Madrid languidece, con un panorama de aguda crisis: 3144 bautizos en 1600, pero sólo 992 en $1605^{78}$. Este mismo año se consumen en Madrid 170.000 arrobas de vino, que pasan a 1.005 .120 en 1607 , con la vuelta de la Corte $^{79}$; el aceite de oliva consumido pasa de 8.398 arrobas en 1605 a

${ }^{69}$ García Barreno, Pedro, «La medicina en el Quijote y en su entorno», La ciencia y el Quijote, ed. José Manuel Sánchez Ron, Barcelona, Crítica, 2005, p. 178.

${ }_{70}$ Marcos Martín, Alberto, «Las ciudades españolas en tiempos de Cervantes», El mundo que vivió Cervantes, com. C. Iglesias, Madrid, SECC, 2005, p.89.

${ }^{71}$ Líter Mayayo, Carmen (com.) Los mapas del Quijote, Madrid, Biblioteca Nacional, 2005, p. 116.

${ }^{72}$ NAVARRO BROTONS, Víctor, «La geografía y la cosmografía en la época del Quijote», La ciencia y el Quijote, cit., p. 18.

73 Ibidem, p. 122.

${ }^{74}$ GARcía TAPIA, Nicolás, Técnica y poder en Castilla durante los siglos XVI y XVII, Salamanca, Junta de Castilla y León, 1989, p. 211.

${ }^{75}$ Ibidem, p. 68.

${ }^{76}$ Ibidem, p. 175 . Vid. pp. 187 y ss.

77 LÓPEZ PIÑERO, José M. ${ }^{\text {, }}$, Ciencia y técnica en la sociedad española de los siglos XVI y XVII, Barcelona, Lábor, 1979, p. 259.

${ }_{78}$ Alvar, Alfredo, Cervantes: Genio y libertad, Madrid, Temas de hoy, 2004, p. 305.

79 Ringrose, David R., Madrid y la economía española, 1560-1850, Madrid, Alianza, 1985, p. 403. 
36.380 en $1607^{80}$. En 1605 los ingresos en Madrid de Peso mayor y correduría fueron de 9.870 reales y 3.800 los de Barca de Arganda ${ }^{81}$. Villalba establece en 26.000 el número de habitantes de Madrid este año ${ }^{82}$, mientras que Barcelona tendría unos 40.000 y Sevilla unos $65.000^{83}$. El rey Felipe III estuvo 164 días en Valladolid en 1605 y ninguno en Madrid ${ }^{84}$.

Frente a ello Valladolid goza de todo el esplendor político y cortesano de la Corte: desde el trajín de la vida política del día a día a la vida extraordinaria de fiestas y celebraciones. Pinheiro ${ }^{85}$ ofrece una detallada descripción de esta ciudad de 15.000 vecinos (historia, ríos, clima, comida, tiendas, casas, calles...) en que no puedo detenerme aquí. Retendré sólo de lo que escribí en otra ocasión:

\begin{abstract}
buena gente, tranquila, sin borrachos, matones, pícaros ni rufianes y un buen nivel de vida, según él, en alimentos, tiendas (105 de dulces, además de figones), paseos por el Prado en verano y el Espolón en invierno, aunque no se libre de suciedad y lodos. Por otra parte, nos informa de la importancia de algunos edificios, belleza de la Plaza Mayor, etc. Desde el punto de vista religioso destaca la abundancia de reliquias, la existencia de 12 iglesias parroquiales, 20 conventos de frailes, 19 de monjas ${ }^{86}$.
\end{abstract}

Pero léase el mencionado texto para una completa información sobre la Corte de Valladolid en 1605.

En la misma idea de esplendor coincide un anónimo viajero de 1605, aunque no deja de señalar la suciedad de la ciudad:

Es una ciudad muy hermosa, con las mejores casas que hemos visto en nuestro viaje, sólo que es desagradable porque no la conservan limpia ${ }^{87}$.

\title{
2. Actividad política
}

En 1605 hace 7 años que ha muerto Felipe II, el monarca reinante, Felipe III, tiene 27 años, y el 8 de abril nace Felipe Dominico Víctor ${ }^{88}$, en

\footnotetext{
${ }^{80}$ Ibidem, p. 436.

${ }^{81}$ Ibidem, p. 406.

82 Villalba PÉReZ, Enrique, La administración de la justicia penal en Castilla y en la Corte a comienzos del siglo XVII, Madrid, Actas, 1993, p. 110.

${ }^{83}$ Burgos, Javier, «La imprenta de Barcelona en el tiempo del Quijote», El Quijote y Barcelona, cit., p. 95.

${ }^{84}$ Alvar, Alfredo, Op. cit., p. 309.

${ }^{85}$ Pinheiro, Tomé, Op. cit., p. 287 y ss.

${ }^{86}$ DíEz Borque, José María, «1605: Vida», cit., p. 15.

${ }_{87}$ ANÓNIMO. The Royal Entertainment (...), Londres, 1605 en Patricia Shaw Fairman, Op. cit., p. 100. Vid. Bennassar, Bartolomé, Valladolid en el Siglo de Oro (...), Valladolid, Ayuntamiento, 1983, pp. 563 y ss.

${ }^{88}$ Sobre el significado de los nombres vid. PinHeIro, Tomé, Op. cit., pp. 95-96.
} 
parto adelantado, pues se esperaba para mayo ${ }^{89}$, que reinará desde 1621 como Felipe IV. Se celebrarán con grandes fiestas en todo el reino, como se verá, el nacimiento y bautizo ( 29 de marzo), pero preocupación hubo por las enfermedades de príncipes, infantes y reina, resultando falso su nuevo embarazo en agosto ${ }^{90}$.

Controla la política el valido duque de Lerma, amado por el pueblo, según Pinheiro:

Es hombre de buena presencia, gentil hombre y de buen carácter, que nadie queda nunca descontento de su persona y porte; y sería adorado si no fuera tan inaccesible para las audiencias, porque es necesario andar dos o tres meses para poderle hablar ${ }^{91}$.

Pero odiado, según el embajador inglés Cornwallis, que traza un panorama desolador de España:

El Rey y el reino [de España] estaban reducidos a tal estado que no podían haber resistido otros dos años [de guerra]; su propia hacienda, sus ingresos y sus impuestos, hipotecados en su mayor parte para devolver el dinero tomado en préstamo; sus nobles empobrecidos y con grandes deudas; sus comerciantes arruinados; sus campesinos en la necesidad más extremada; sus métodos de obtener dinero aumentando el valor de éste y otros procedimientos de este tipo, todos agotados; sus posibilidades para obtener crédito, muy disminuidas, a causa de la falta de seguridad de su estado durante la guerra con Inglaterra; los súbditos de sus muchos y alejados dominios, sometidos obedientes por la fuerza y no por cariño y sentido del deber, eran más bien una preocupación y una carga que un alivio y un apoyo para él. Él era muy joven y por eso no tenía la veneración de su pueblo; y aun menos por permitir que le gobernase un hombre [Lerma] generalmente odiado por su propio país; su fuerza en el mar, demasiado débil para proteger los puertos de la península, sin hablar de las Indias y del regreso a casa de «la flota de la plata...».92

Hay que interpretarlo desde el estudio, edición y valoración de las cartas del citado Cornwallis ${ }^{93}$. Lo visto está en la misma línea de lo que un año antes había escrito Sir Walter Raleigh ${ }^{94}$.

El Rey de España es ahora tan pobre que ha mandado a sus jesuitas que pordioseen para él a las puertas de todas las iglesias de España.

${ }^{89}$ CABRERA, Luis, Op. cit., p. 233.

90 Ibidem, pp. 235; 255-258; 262; 266.

${ }^{91}$ Pinheiro, Tomé, Op. cit., p. 77.

92 CoRnwallis, Charles, carta en Patricia Shaw Fairman, Op. cit., pp. 268-269.

93 Vid. nota anterior y además Stoye, J., English travellers abroad 1604-1667, New Haven y Londres, 1989 y ThOMPSON, I.A.A., «Sur Charles Cornwallis y su 'Discurso sobre el Estado de España' (1608)», La monarquía hispánica en tiempos del Quijote, cit., pp. 65-101.

${ }_{94}$ Shaw FaIRman, Patricia, (Op. cit., p. 268) señala que Raleigh era partidario de que Inglaterra continuara la guerra con España. 
Sus ingresos están hasta tal punto hipotecados, que, de veinticinco millones, no le quedan libres más de cinco; sus barcos están viejos y podridos y sus súbditos, en general, excesivamente pobres.

Recientemente ha recibido muchas ofensas y ha tenido muchas pérdidas, $y$, en el Perú, muchas de las mejores y principales ciudades han sido recobradas por los indígenas.

Y, generalmente, una vez que las grandes monarquías empiezan a decaer, por poco que sea, pronto llega detrás su destrucción.

El imperio español ha sido bien sacudido y ha empezado, en años recientes, a decaer; y es un principio filosófico que omnis diminutio est preparatio ad corruptionem... ${ }^{95}$.

Es cierto que entre 1605 y 1610 hubo una grave depresión económica ${ }^{96}$, y entre 1601 y 1605 se había reducido la plata que llegaba de las Indias ${ }^{97}$.

Todo esto guarda relación con la firma del tratado de paz con Inglaterra, publicado el 21 de noviembre de $1604^{98}$ y ratificado el 15 de junio de 1605 en Valladolid ${ }^{99}$. Ni Raleigh ni Cornwallis eran partidarios de la firma de dicho tratado de $\mathrm{paz}^{100}$. Pero fue el hecho más importante en política exterior de España en nuestro año de 1605. Así lo muestran el recibimiento, fiestas, agasajos a la embajada inglesa, que permanece en Valladolid del 26 de mayo al 18 de junio de $1605^{101}$, aunque también hubo críticas, como veremos.

En política interior cabe destacar la llegada de emisarios de Aragón, en octubre, para pedirle al rey Cortes, y la decisión de Felipe III, en noviembre, de ir a Zaragoza después de Pascua Florida ${ }^{102}$. Precisamente este año de 1605 el cardenal Ascanio Colonna, virrey de Zaragoza, publica un Memorial sobre el estado de Zaragoza ${ }^{103}$.

Viajan los reyes a Tordesillas, Lerma y se preparan para ir a Portu$\mathrm{gal}^{104}$. Pero, como es obvio, la actividad política diaria supuso multitud de actuaciones en las que no puedo entrar aquí. Por otra parte, entre la nobleza cortesana serían motivos de conversación y preocupación las intrigas de

\footnotetext{
95 Ibidem.

96 LÓPEZ PiÑERO, José María, Op. cit., p. 387.

97 Thompson, I. A. A., «La guerra y el soldado», España en tiempos del Quijote, cit. p. 167

98 Cabrera, Luis, Op. cit., p. 230. DíAZ Plaja, Fernando, El siglo XVII, Madrid, Instituto de Estudios Políticos, 1957, pp. 9-14.

99 SAnZ CAMAÑes, Porfirio, «España e Inglaterra: Conflicto de intereses y luchas de poder entre 1585 y 1604», La monarquía hispánica, cit., p. 588.

100 Vid. notas 92 a 95.

101 PinHeIRO, Tomé, Op. cit., pp. 78-86; 160-161.

102 Cabrera, Luis, Op. cit., pp. 261-265.

103 CAstronuovo, Marta, «El cardenal Ascanio Colonna y Miguel de Cervantes», Cervantes a la Mediterrània, com. Pere Jordi Figuerola, Barcelona, Museu Diocesà, 2005, pp. 67-75.

104 CABRERA, Luis, Op. cit., pp. 261-265; passim.
} 
palacio, los nombramientos de cargos públicos, matrimonios, herencias, de lo que Cabrera nos ofrece numerosos testimonios, cuya consideración está fuera de lugar aquí. Pero sí me parece importante destacar, habida cuenta del peso de las órdenes de caballería, que en 1605, en Valladolid y por Luis Sánchez, se publica la Copilación de las leyes capitulares de la orden de la Caballería de Santiago.

\section{La guerra}

No es el de 1605, como los siguientes, buen año para los ejércitos españoles. Hubo alguna victoria en el año anterior ${ }^{105} \mathrm{y}$ en éste, como la toma de la plaza de Wachtendork ${ }^{106}$, victoria de Frisa ${ }^{107}$. Se construyen 6 galeras para la Corona de Castilla ${ }^{108}$, y es nombrado en marzo Spinola Superintendente de Hacienda «con poderes absolutos sobre el tesoro militar»; recibirá «grandes cantidades de provisiones» ${ }^{109}$ y se reforma el almirantazgo de Flandes ${ }^{110}$. Pero la sangría de la guerra y las derrotas continúan. Hay motines en los tercios de Flandes entre 1600 y $1606^{111}$, los holandeses construyen en el invierno de 1605-1606 una cadena de «fortines, blocaos y reductos defensivos» ${ }^{112} \mathrm{y}$ atacan también en las Indias en diciembre, así como otros piratas en alta mar en octubre ${ }^{113}$, lo que reduce el rico cargamento de los galeones que llegaban a Sevilla, aunque en enero de 1605 llegaron con 12 millones de pesos ${ }^{114}$.

Continúa el asedio de los turcos y preocupa tener seguro el norte de África, así la expedición del marqués de Villafranca al norte de Marrue$\cos ^{115}$. Pero valgan como testimonio de sangrientas derrotas en este año de 1605, la de Dunquerque y la de Mahometa. De la primera escribe Cabrera:

En el paraje de Dunquerque salieron gran cantidad de navíos holandeses y pelearon con los nuestros que eran seis, y mataron cuatrocientos hombres,

105 Agulló, Mercedes, Relaciones de sucesos. I: 1477-1619, Madrid, CSIC., 1966, p. 45.

106 Díaz Plaja, Fernando, Op. cit., p. 25.

107 CABrera, Luis, Op. cit., p. 266.

108 Thompson, I. A.A., Guerra y decadencia (...), Barcelona, Crítica, 1981, p. 375.

109 PARKER, Geoffrey, El ejército de Flandes y el camino español 1567-1659, Madrid, Alianza, 1986, p. 299.

110 ThOMPSON, I. A. A., «La guerra», cit., 194.

111 Albi de la Cuesta, Julio, De Pavía a Rocroi (...), Madrid, Balcan editores, 1999, p. 189.

112 PARKER, Geoffrey, Op. cit., p. 51.

${ }^{113}$ CABrera, Luis, Op. cit., pp. 264; 267.

114 Ibidem, p. 233.

115 Rivero RoDríGuEZ, Manuel, «¿Monarquía católica o hispánica?: La encrucijada de la política norteafricana entre Lepanto (1571) y el proyecto de la jornada real de Argel (1618)», La monarquía hispánica, cit., p. 610. 
con seis capitanes, y nos tomaron dos navíos, y los demás se hubieron de recoger a Inglaterra ${ }^{116}$.

Pero debió de conmocionar al mundo hispano el año de publicación del Quijote el desastre de Mahometa: sólo se salvaron 72 soldados de los 800 del tercio de Sicilia; el Maestre de Campo, Andrés de Silva, fue cortado en dos, los musulmanes cortan las cabezas de los muertos y las cuelgan de los cuellos de los supervivientes, y gráficamente se describe la vuelta a Palermo de los derrotados: «los alaridos de las mujeres hacían llorar los remos de las galeras» ${ }^{117}$. Ésta era la dura realidad de la guerra más allá y más acá de los ideales belicistas más o menos asumidos.

\section{VIDA RELIGIOSA}

\section{Vida religiosa y control}

Bien conocida es la importancia de la religión en la formación del imaginario colectivo y organización de conciencias en la España del XVII. Sabemos la función y alcance de ceremonias litúrgicas, procesiones, sermones y la importancia de las fiestas y religiosidad popular. No es lugar éste para entrar en consideraciones generales sobre estas cuestiones. Me limitaré sólo a algunos datos particulares en el año que nos ocupa.

En 1605 hubo tres papas: Clemente VIII, León XI Y Paulo V. El 8 de marzo muere Clemente VIII y es elegido Alejandro Octaviano de Médici, que adopta el nombre de León XI. Su pontificado fue brevísimo, pues según Pinheiro fue de 27 días: «18 en pie y 9 en cama» ${ }^{118}$. Aunque tenía mala salud se difundió la sospecha de que había muerto envenenado ${ }^{119}$. En abril España estaba pendiente de recibir noticias de la elección de nuevo papa $^{120}$, de la que se informará, entre muchas otras, en la Relación de la elección del Sumo Pontífice Paulo V. ${ }^{121}$ Fue elegido Camilo Borghese, que adoptó el nombre de Paulo V y su pontificado duró hasta $1621^{122}$. Se vivía con intensidad la elección de nuevos pontífices, pues no sólo circulaban pronósticos y se celebraba con procesiones, misas, luminarias, sino que se leían, copiaban y prestaban relaciones de los concláves.

Las procesiones eran una forma arraigada de religiosidad oficial y popular. Baste, como testimonio, la del Corpus en Salamanca el 9 de junio de 1605 , de la que el citado estudiante salmantino da minuciosa cuenta de la presencia de pendones, imágenes, parroquias, órdenes religiosas, custo-

116 CABRERA, Luis, Op. cit., p. 255.

117 Albi De la Cuesta, Julio, Op. cit., pp. 324-325.

118 Pinheiro, Tomé, Op. cit., p. 67.

119 Ibidem, p. 68.

${ }^{120}$ CABrera, Luis, Op. cit., p. 240. Diario de un estudiante, cit., p. 331. 
dia, palio, de una gran complejidad y espectacularidad ${ }^{123}$. Pueden encontrarse otros testimonios en Pinheiro sobre las de Semana Santa, Corpus, etc. ${ }^{124}$.

Los sermones tenían un gran poder de convocatoria e influencia, llegando a ser una forma de espectáculo cuando «predican como comediantes» ${ }^{125}$. Sabemos que los actores asistían a los sermones para imitar formas y modos de los predicadores, encaminadas a convencer y conmover. Para 1605 el estudiante de Salamanca proporciona valiosos datos, día a día, de los sermones en Salamanca y de los ejemplos que utilizan los predicadores, lo que puede ser útil para reconstruir esta peculiar forma de comunicación púlpito-feligrés y el sentido y alcance de la misma ${ }^{126}$. Pero no hay aquí posibilidad de ir más allá en esto.

En el espacio más íntimo de la religiosidad está la relación confesorpenitente, es decir, el pecado, la culpa y su castigo. Muy curiosos son los testimonios de pecados y penitencias de un joven estudiante en la Salamanca de 1605:

7 de abril

Mi confessai con Fra Carlo di Tornai Franzese di Santo Agostino.

Dodeca dolcitudine.

Tessara toccamento et baci.

Due bolte le ruffiane.

De libri.

Esame. pentimento. ingratitudine con Dios.

Propósito di non peccar piu.

Penitenza imposta. Trascuraggine nella comunione et doppo.

Della fede. delli augurioi.

De giuramenti. digiuni.

Giuoco, bugiai. spese superflue. poco studio.

Guardare, toccare, parlare, pensare lascibo.

Sogni.

Negligenza. accidia.

Negligenza nella correttion fraterna.

Murmuratione in particulare de religiosi.

Referito alcuni peccati mortali.

Rallegrarsi de udir male et peccati altrui.

Dar occasione che alcuna persona gli dica.

Del boto della castita.

Penitenza

Digiunare il Benerdi santo a pane et acqua.

121 Agulló, Mercedes, Op. cit., p. 45.

${ }^{122}$ LaboA Gallego, Juan María, Historia de los papas, Madrid, La esfera de los libros, 2005, pp. 331-336.

${ }^{123}$ Diario de un estudiante, cit., pp. 360-361.

124 Pinheiro, Tomé, Op. cit., pp. 42 y ss.; 120.

${ }^{125}$ Ibidem, Op. cit, pp. 43 y ss.

126 Diario de un estudiante, cit., passim. 
Sei rosarioi di nostra signora ogni sabbato tra pasqua et pasqua.

Y en la confesión de 10 de agosto la penitencia fue: «Sette salmi et le preci. Un responso. Digiurnare un benerdi» por los pecados: «Pollutione voluntaria con donne. Fornicationi [...] adulteriori se bene con puttane. Toccamenti, baci, sogni, pensieri, parole... mirare» ${ }^{127}$. Muchas eran las iglesias, conventos y ermitas, pero algunas nuevas se construyeron en 1605: en Madrid, por ejemplo, la ermita del Ángel de la Guarda o la iglesia del convento de Carmelitas Descalzas ${ }^{128}$. Algunos monasterios parece que fueron auténticas fincas de recreo, como el benedictino entre Villagarcía y Simancas, donde no sólo había, como es propio, riqueza de cuadros, capas pluviales, etc., sino «una finca cercada por un muro de piedra, el cual mide una legua o más de circunferencia: dentro hay toda clase de caza real, como faisanes, perdices, liebres, conejos, etc.» ${ }^{129}$.

Las ceremonias extraordinarias cautivaban por su aparatosa espectacularidad, así, por ejemplo, la consagración del obispo de Ciudad Rodrigo el 13 de noviembre de 1605:

Si fece la Consacratione del Vescouo di Ciudad Rodrigo Fray Pedro Ponze de Leon fratel del Duca di Arcos in San Stefano. Consacròle el Vescouo di Salamanca, assistieron gli altri tre detti, il consacratore uestito di uerde, et con pianeta, gli altri con piuiali bianchi, et con mitria; il Vescouo nuouo con berreta sino all'ultimo della messa, che gli messero la mitria. Lessero prima le bolle, et altre cirimonie. Aiuto il nuouo Vescouo la Confessione al consacrante et quando si communicò stette in un angulo dell'altare, dicendo le istesse parole della Consacratione et si communicò della mita dell'istessa hostia, et sangue santissimo...

...Offerse il nuouo Vescouo 2 pani dorati, 2 fiaschi, 1 di acqua, altro di uino, pur dorati, e 2 torcie, che le portorno Don Fernando di Cordoua, Don Fadrique di Toledo, i 2 minori Pimentelli, et il del Carpio. Dette ad multos annos a i 4 Vescoui in ginocchioni, dette la benedittione al popolo doppo il Vescouo di Salamanca.

Tutti i uescoui et questi Signorotti sino al numero di 30 desinorno in casa il Vescouo di Salamanca.

Don Antonio dormi in mia casa ${ }^{130}$.

La cara menos grata de todo esto era el control, la censura, la persecución inquisitorial. Valgan como ejemplos significativos algunos casos: proceso al catedrático de Matemáticas de Salamanca González y a Luis Rosicler ${ }^{131}$, proceso por brujería a García Bartolomé y a una mujer de

${ }^{127}$ Ibidem, pp. 334; 387-388.

128 LeÓn Pinelo, Antonio de, Anales de Madrid (desde el año 447 al de 1658), ed. P. Fernández, Madrid, CSIC., 1971, pp. 184-185.

129 TRESWELl, Robert, Op. cit., p. 99.

130 Diario de un estudiante, cit., p. 426.

131 Cirac Estopañán, Sebastián, Los procesos de hechicería en la Inquisición de Castilla la Nueva (...), Madrid, CSIC., 1942, p. 261. 
Argamasilla ${ }^{132}$, prisión de moriscos en Valencia ${ }^{133}$, que contrasta, claro, con el rumor infundado de que el rey traería a 10.000 judíos para que se ocuparan de los negocios ${ }^{134}$.

Se censuran libros, como Consideraciones sobre los evangelios de fray Hernando de Santiago, mercedario ${ }^{135}$. Interviene la Inquisición en la polémica entre jesuitas y dominicos por De auxiliis, y porque intervenga en todo Roma y no la Inquisición española ${ }^{136}$.

\section{VIDA LÚDicA: LA FIESTA Y EL JUEGO ${ }^{137}$}

La fiesta, tanto la popular como la cortesana, rompe el ritmo del trabajo y de la vida diaria y tiene un papel fundamental en la vida en sociedad. El año de gracia de 1605 fue esplendoroso en fiestas y celebraciones, particularmente en la corte de Valladolid y, en especial, para festejar el nacimiento y bautismo de Felipe Dominico Víctor, futuro Felipe IV, aunque también con otros motivos, como, por ejemplo, la llegada del Almirante de Inglaterra. Disponemos de cumplida información de estas fiestas cortesanas, pero antes de referirme a ellas quiero hacer breve mención de otros aspectos particulares de la vida lúdica, como son las fiestas populares, que he estudiado ampliamente en otro lugar ${ }^{138}$. La fiesta de San Juan era celebrada con bailes, enramadas, música, canciones, toda la noche ${ }^{139} \mathrm{y}$ «en la noche de San Pedro hay las mismas fiestas que en la de San Juan» ${ }^{140}$. Pero también la fiesta de Santa María Magdalena, el 22 de julio:

Día de Santa María Magdalena es uno de los más hermosos días que tiene Valladolid, porque como su iglesia está en el Prado (...) hay uno de los mayores concursos de la corte que tiene el año ${ }^{141}$.

El Prado de la Magdalena era el pase de verano - verde y hermoso, pues lo riegan todos los días-, donde se juntaban hasta 300 coches «sin otro intento que ver y ser vistos». En él se merendaba y galanteaba ${ }^{142}$. El Espolón era, en cambio, el paseo de invierno, como dije. También era

132 Ibidem.

133 CABRERA, Luis, Op. cit., p. 240.

134 Ibidem, p. 243.

135 PAZ Y MEliá, A., Papeles de Inquisición - Catálogo y extractos, Madrid, PAHN, 1947 , p. 386.

136 Ibidem, pp. 315-316. Diario de un estudiante, cit., p. 367.

137 Retengo aquí en parte, con alteraciones, lo que escribí en «1605: vida», cit., pp. 18-21.

138 Díez Borque, José María, «Celebraciones y fiestas», cit.

139 PinheIRO, Tomé, Op. cit., p. 175.

140 Ibidem, p. 188.

141 Ibidem, p. 265.

142 Ibidem, pp. 57; 113; 140; 180. 
costumbre nadar en el río, con la desgracia de algún ahogado, como el 26 de junio ${ }^{143}$.

A todos los niveles las expansiones gastronómicas eran componentes destacados de la vida lúdica: desde las populares meriendas a los banquetes de la nobleza, hasta con 2.200 platos $^{144}$, llevando, a veces, la comida de las meriendas al descubierto para exhibición ante el pueblo ${ }^{145}$.

La fiesta de los toros, asociada a diversas celebraciones, gozaba del favor popular, tanto que en junio se hizo un tablado en Valladolid para 12.000 personas ${ }^{146}$. Hubo toros «ben cattivi» por San Juan ${ }^{147}$, para fiestas universitarias, en junio, en Salamanca, con premios, invenciones, sortijas ${ }^{148} \mathrm{y}$, naturalmente, para el Corpus:

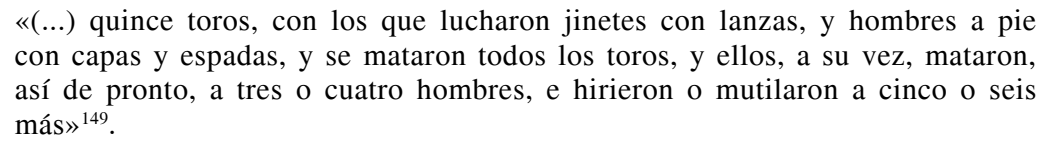

Precisamente el Corpus era una de las fiestas más arraigadas en que se conjugaba la celebración popular - que genera un rico folclore- con la organizada por la jerarquía y el poder. Conocemos, para 1605, danzas, procesiones, piezas teatrales en varias ciudades de España (Sevilla, Salamanca, Oviedo, Burgos...), pero no puedo detenerme aquí en ello por razones de espacio, aunque lo trataré por extenso en otro estudio ${ }^{150}$.

Las fiestas por el nacimiento y bautismo del futuro Felipe IV fueron esplendorosas en la corte vallisoletana y en toda España. De Sevilla, Salamanca tenemos detalladas informaciones de De Sommaia, Morales ${ }^{151}$, pero destacaron las fiestas cortesanas de Valladolid, que sumaron en este año de 1605 las que se hicieron por la llegada del embajador inglés, tanto que se dictaron «medidas especiales de vigilancia en Valladolid por las celebraciones del nacimiento y bautismo del príncipe en $1605 »^{152}$.

De las fiestas cortesanas en Valladolid encontramos en Pinheiro, Cabrera, Agulló, Alvar, Canavaggio, cumplida información de las mascara-

\footnotetext{
${ }^{143}$ Ibidem, pp. 186-187.

144 Ibidem, p. 118.

${ }^{145}$ Ibidem, pp. 307-309.

146 Ibidem, p. 122.

${ }_{147}$ Diario de un estudiante, cit., p. 367.

148 Ibidem, p. 359.

149 ANÓNImO, The Royal, cit., p. 237.

${ }^{150}$ Lo trataré por extenso en mi estudio citado sobre el teatro de 1605. De danzas del Corpus nos informan con detalle los estudios citados de Sentaurens, De Miguel, García Valdés, Diario de un estudiante, etc.

${ }^{151}$ Diario de un estudiante, cit., pp. 337 y ss.; MoRAles PADRÓn, Francisco, Memorias de Sevilla, Sevilla, Monte de Piedad, 1981, p. 27.

${ }^{152}$ Villalba PÉreZ, Enrique, Op. cit., pp. 267-268.
} 
das, saraos, encamisadas, luminarias, cortejos, arquitecturas efímeras, torneos, toros, cañas, fuegos artificiales, trompetas, chirimías en las calles, carreras, muestras de la guardia, lujos de vestidos y joyas, rituales ceremoniales, etc. En absoluto puedo entrar en todo esto aquí. Sólo quiero recordar que hasta hubo colaboración de pintores como Carducho «uno de los más famosos pintores que su majestad tiene» ${ }^{153}$.

Canavaggio se refiere al recuerdo cervantino de estos festejos en $L a$ Gitanilla:

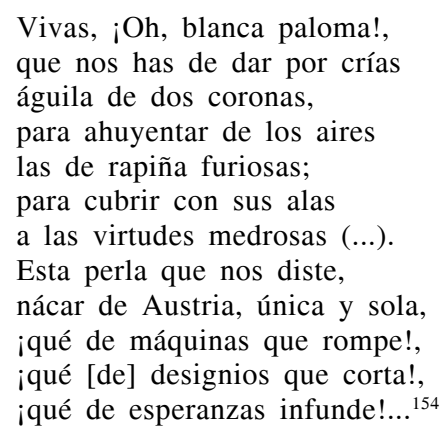

Las mismas fuentes citadas nos muestran la riqueza de las fiestas públicas por la llegada del embajador inglés, pero Canavaggio y Alvar ${ }^{155}$ recogen un soneto satírico anónimo que fue atribuido a Góngora:

Parió la Reina; el luterano vino con seiscientos herejes y herejías; gastamos un millón en quince días en darle joyas, hospedaje y vino.

Hicimos un alarde o desatino, y unas fiestas que fueron tropelías, al angélico Legado y sus espías del que juró la paz sobre Calvino.

Bautizamos al niño Dominico que nació para serlo en las Españas; hicimos un sarao de encantamento.

Quedamos pobres, fue Lutero rico; mandáronse escribir estas hazañas a don Quijote, a Sancho, y su jumento.

153 Alenda, J., Relación de solemnidades y fiestas públicas de España, Madrid, Sucesores de Rivadeneyra, 1903, p. 141.

${ }^{154}$ Canavaggio, Jean, Op. cit., p. 186.

155 Ibidem, p. 187. Alvar, Alfredo, Op. cit., p. 316. 
Canavaggio ${ }^{156}$ subraya la popularidad ya del Quijote «en menos de seis meses», que podría quedar corroborada con la alusión que recoge el historiador Pinheiro da Veiga a un posible entremés en el marco del festajo:

Apareció un Don Quijote que iba en primer término como aventurero, solo y sin compañía, con un sombrero grande en la cabeza y una capa de bayeta y mangas de lo mismo, unos calzones de velludo y unas buenas botas con espuelas de «pico de pardal» batiendo las ijadas de un pobre cuartago sucio, con una matadura en el borde del lomo, de las guarniciones del coche y una silla del cochero; y Sancho Panza, su escudero, delante. Llevaba unos anteojos para mayor autoridad, y bien puestos, y la barba levantada, y en medio del pecho una insignia de Cristo $^{157}$ :

Para comprender cómo se vivía la fiesta es muy curioso el dato del préstamo de objetos de adorno para engalanarse y lucir en la celebración ${ }^{158}$.

La fiesta cortesana era, como sabemos, participación para unos pocos y gran espectáculo para la mayoría. Pero había otros espectáculos para la pública diversión y regocijo (aparte del teatro, el espectáculo por excelencia, ya visto). Así, entre otros muchos, el de volteadores en Ávila en $1605^{159}$, carreras de caballos en la plaza de Salamanca, en julio, o de anillos y sortija en septiembre y octubre ${ }^{160}$. Mujeres e hijas jugaban al pistolete en Valladolid $^{161}$. Seguía siendo popular en Valladolid el curioso juego de «Alcayado con Chueca», que nos describe Lhermite:

El juego es muy entretenido, pueden participar en él muchas personas a la vez y cabe decir que cuantas más personas jueguen tanto más divertido resulta. Los jugadores se reparten en dos grupos y se colocan en una llanura muy despejada, y los límites del juego no pueden sobrepasar la extensión de este terreno. Los jugadores se mueven todos juntos y se entremezclan unos con otros. Uno de los dos grupos golpea la pelota para hacerla avanzar, mientras que el otro trata de repelerla, y demuestran ambos equipos tal destreza en estas acciones que nunca esperan a que la bola toque o caiga al suelo, sino que la cogen en el aire alargando rápidamente el brazo, y no es raro que la envíen hacia atrás, a una distancia que equivale al doble de la que el primer grupo la ha hecho avanzar previamente, y hay en este juego tantos gritos $\mathrm{y}$ bromas, que yo creo que los contendientes no pueden obtener mayor placer en el mundo, aunque no es menor la diversión que proporcionan a los espectadores los divertidos saltos, vueltas, piruetas y pasos que pueden ver practicar tanto a los jóvenes galanes como a las muchachas del pueblo, que a veces intervienen también en este juego ${ }^{162}$.

156 Canavaggio, Jean, Op. cit.

157 Pinheiro, Tomé, Op. cit., p. 194.

${ }_{158}$ Diario de un estudiante, cit., pp. 341; 342; 345.

159 Bernaldo De Quirós, José A., Op. cit., p. 107.

${ }^{160}$ Diario de un estudiante, cit., pp. 367; 403; 408.

161 Pinheiro, Tomé, Op. cit., p. 145.

${ }^{162}$ El Pasatiempos de Jean Lhermite, estudio Jesús Sáenz de Miera. Traducción José Luis Checa Cremades, Aranjuez, Doce Calles, 2005, pp. 596-597. 


\section{VIDA DIARIA}

\section{Los trabajos y los días: la terrible sequía}

Mal año para el campo fue el de 1605, en una España agrícola sometida a los incontrolables avatares climatológicos. Muy dura fue la sequía en Valladolid ${ }^{163}$ y en el resto de España: Andalucía, agravada por una plaga de cigarrones, La Mancha ${ }^{164}$, y no sirvieron para mucho las rogativas. La consecuencia fue el hambre y la subida de precios del trigo y de la cebada. Según Cabrera la fanega de trigo sube de 14 reales a 18 y la de cebada de 7 a 9 reales ${ }^{165}$, mientras que Morales para Sevilla afirma que «valió una fanega de trigo doce ducados y una hogaza cuatro reales» ${ }^{166}$. En todo caso no fueron los sufridos labradores de los campos de España quienes se beneficiaron de estas subidas, sino quienes tiene «pan de renta», como el cardenal de Toledo, a quien la subida le supuso unas ganancias de 40.000 ducados $^{167}$.

Baste con el testimonio de la sequía, que era una alteración grave en el vivir diario de una España fundamentalmente agrícola, sin ir aquí más allá en otras consideraciones sobre los trabajos y los días.

\section{Sucesos y hechos extraordinarios}

La vida diaria del trabajo con sus problemas, miserias, contingencias como la sequía devastadora, se veía alterada en su monótono discurrir por sucesos que rompían el ritmo de los días. Sin duda, serían tema de conversación, este año de gracia de 1605, robos, asesinatos, estafas, castigos, que por su carácter extraordinario gozaban de gran atracción popular. Asesinatos hubo, como el del paje de Duque de Lerma en enero ${ }^{168}$, o el de Juan de Persia, hijo de Alí Bac Bayat «de la cámara del sufí Mohamet», por el embajador de su nación en Valladolid, por haberse hecho católico ${ }^{169}$, cuyo entierro muestra, con viveza, el trato dado a los asesinados:

Muy sentida fue su muerte de todos cuantos le conocían y, sin embargo, su cadáver fue puesto con poco respeto dentro de un carro de mimbres, cubierto con un paño sucio, con las piernas de fuera y arrastrando. Seguían al carro

\footnotetext{
163 BenNASSAR, Bartolomé, Op. cit., p. 48-49.

164 CABRERA, Luis, Op. cit., p. 231.

165 Ibidem, p. 236.

166 Morales, Op. cit., p. 26.

167 CABrera, Luis, Op.c it., p. 262.

168 Ibidem, p. 239.

169 García Mercadal, J., Viajes de extranjeros por España y Portugal, Salamanca, Junta de Castilla y León, 1999, II, p. 662.
} 
como unos trescientos muchachos del pueblo, pugnando por destapar el cuerpo muerto y gritando a más no poder: «iPor Mahoma!». De esta manera le llevaron a un barranco próximo al pueblo de Argelés, y lo arrojaron allí, comiéndole los perros las piernas por no haberle dado decente sepultura; ${ }^{170}$

También serían comentados el asesinato del emperador de Persia ${ }^{171}$; la muerte de personas importantes, como el príncipe de Piamonte, que muere en Valladolid el 9 de febrero de «vaiolo et tabardillo» ${ }^{172}$, o la de Castillo de Bobadilla, Fiscal de la Real Audiencia y Chancillería de Valladolid los primeros días de septiembre ${ }^{173} \mathrm{y}$, naturalmente, las muertes por accidente, como la del menino de la reina, que muere ahogado en abril ${ }^{174}$, o la de una mujer en el río el 13 de mayo ${ }^{175}$.

Riñas y pendencias las hubo con frecuencia: el 24 de abril entre el conde de Saldaña y el duque de Maqueda'176; el 12 de mayo hieren a un correo de su majestad que iba a Sevilla ${ }^{177}$; el 24 de mayo en Salamanca entre médicos ${ }^{178}$; el 30 de mayo «il vescovo descalabrado en los descalços» en Salamanca ${ }^{179}$; el 6 de junio entre pajes, en Valladolid, por el tratamiento de señoría y merced ${ }^{180}$, y el mismo día en Salamanca el racionero Sánchez hiere al alguacil del obispo ${ }^{181}$.

Entre 1604 y 1605 se produjo la sonada estafa de 30.000 ducados por un secretario del Consejo de Finanzas ${ }^{182}$. No faltaron robos en las calles, como el del 14 de junio en que un joven roba en Valladolid una medalla de diamantes, aunque los castigos eran fuertes; se le condena a muerte, pero le conmutan la pena por la de galeras toda la vida ${ }^{183}$. Los azotes eran castigo para los ladrones, así el 26 de mayo a unos niños en Salamanca, por robo $^{184}$. A los rufianes se les dan 500 azotes y si intentan huir se les corta la mano ${ }^{185}$. La ordenanza establece:

Ordenamos y mandamos que todo el que fuere hallado de noche con escala de cuerda, ganzúa o genovés, como instrumentos perjudiciales a la moneda y

\footnotetext{
170 Ibidem, pp. 662-663.

171 Pinheiro, Tomé, Op. cit., pp. 26-27; Alvar, Alfredo, Op. cit., p. 317.

172 Diario de un estudiante, cit., p. 310.

173 TOMÁs y VAliente, Francisco, Gobierno e instituciones en la España del Antiguo Régimen, Madrid, Alianza, 1982, p. 195.

174 CABRERA, Luis, Op. cit., p. 239.

175 Diario de un estudiante, cit., p. 350.

176 PinheIRO, Tomé, Op. cit., pp. 64-65.

177 Diario de un estudiante, cit., p. 350.

178 Ibidem, p. 353.

179 Ibidem, p. 355.

180 PinHEIRO, Tomé, Op. cit., pp. 115-116.

181 Diario de un estudiante, cit., p. 358.

182 Canavaggio, Jean, Op. cit. 172.

183 Pinheiro, Tomé, Op. cit., p. 149.

184 Diario de un estudiante, cit., p. 354.

185 Pinheiro, Tomé, Op. cit., p. 307.
} 
patacas de España, sea azotado, porque es gravemente sospechoso a los Reales Castellanos ${ }^{186}$.

Para los asesinos estaba establecida la pena capital, así, en Salamanca, el 19 de octubre, garrote y degüello en la plaza, con la cabeza puesta en un palo durante 24 horas $^{187}$,o el 23 de diciembre «dicen que en Valladolid han dado garrote a doña Antonia Miñaia por la muerte de don Mendo» [en junio de 1605$]^{188}$. También eran perseguidos los falsos pobres y mendigos, como se establece en las Disposiciones de Valladolid de $1605^{189}$. Pero estaba en Valladolid la Real Audiencia y Chancillería para «revisar las causas apeladas a los tribunales menores de Castilla» ${ }^{190}$. Los agentes en la Cancillería de Valladolid cobraban 30.000 maravedíes al año, los abogados entre 16.000 y 20.000 , según la consulta de 14 de enero de $1605^{191}$.

Fuera de los hechos delictivos hubo sucesos que debieron impresionar, como la pérdida de los galeones que iban de Cartagena a La Habana, en diciembre, ahogándose el general Luis de Córdoba ${ }^{192}$, o el incendio de la iglesia de San Benito, que supuso unas pérdidas de 10.000 ducados ${ }^{193}$.

Al margen de delitos y hechos fuera de lo ordinario hay que mencionar sucesos anormales que excitaban la curiosidad y conmovían la credulidad popular, que concedía poderes extraordinarios a los eclipses, culpándolos de enfermedades - como al de septiembre ${ }^{194}$ - u otorgaba valor premonitorio a los «grandes fuegos en el cielo», «grandes señales en el cielo» en noviembre ${ }^{195}$. Signos de mal agüero eran romperse el zapato, ladrar los perros, cantar la gallina como el gallo, caer la sal, el gato negro, los martes ${ }^{196}$. Por otra parte, los milagros y milagrerías atraían a todos, y baste citar para nuestro año el del hermano Francisco, que tenía color de vivo a los diez días de haber muerto ${ }^{197}$.

\section{Colofón: Cervantes en 1605}

Tras el camino recorrido hasta aquí por la España de 1605, con jalones que han ido marcando aspectos destacables de vida y cultura, habría que

\footnotetext{
186 Ibidem, p. 44.

187 Diario de un estudiante, cit., p. 414.

188 Ibidem, pp. 425; 85.

189 Villalba PÉREZ, Enrique, Op. cit., p. 250

190 Kagan, Richard L., Pleitos y pleiteantes en Castilla, Salamanca, Junta de Castilla y León, 1991, p. 105.

191 Ibidem, p. 36.

192 Morales, Francisco, Op. cit.

193 CABRERA, Luis, Op. cit., p. 241.

194 Ibidem, p. 259.

195 Agulló, Mercedes, Op. cit., p. 45. Morales, Francisco, Op. cit., p. 27.

196 Pinheiro, Tomé, Op. cit., p. 164.

197 CABrera, Luis, Op. cit., p. 234.
} 
detenerse, como punto final, en la vida de Cervantes el año de publicación de la primera parte del Quijote. Remitiré, pues espacio obliga, a las biografías de Astrana Marín, Mckendrick, Canavaggio, Alvar, etc. ${ }^{198}$ Recordaré que Cervantes, con la Corte, estaba en Valladolid, viviendo en la calle del Rastro, «rodeado de mujeres», como se ha dicho: esposa, hijas, dos hermanas y una sobrina.

Había llegado a la madurez de los 57 años, faltaban 11 para su muerte, y tenía a sus espaldas una vida llena de sinsabores, experiencias militares, cautiverio... Aunque pudiera llevar ahora en Valladolid una vida sedentaria y quizá tratara con Dantisco, Góngora, Quevedo ${ }^{199}$, no faltan este año sucesos que perturban el discurrir de sus días con falsas acusaciones, como ya le había ocurrido otras veces. Se trata ahora de la falsa inculpación en la muerte de Ezpeleta, que una vez más le llevó a la cárcel —esa honda huella en la vida de un hombre obsesionado por la libertad (Rosales)—, aunque saldrá a los pocos días.

Pero 1605 es, claro, para Cervantes el año del Quijote. En Valladolid terminaría, en 1604, la redacción de la primera parte, la revisaría en el verano, Robles le pagaría 1.500 reales y la obra se pondría a la venta a 290 '5 maravedías ${ }^{200}$. El éxito fue rápido - antes me he referido a elloya que, como escribe Canavaggio, «tres meses habían bastado, pues, para que el Quijote bata todos los records de venta» ${ }^{201}$. Pero no faltaron los problemas, como se deduce del «Poder otorgado por Miguel de Cervantes a favor de Francisco de Robles, Diego de Alfaya y Francisco de Mar para querellarse contra los que han impreso o quieran imprimir El Quijote en Castilla o en Portugal (12 de abril de 1605)» ${ }^{202}$. No hace al caso, por otra parte, detenerse aquí en cuestiones editoriales, debatidas por la crítica, características materiales y proceso de edición, Quijote corto manuscrito, difusión a finales de 1604, etc.

Cervantes, por fin, dejaría Valladolid en otoño de 1605, como señalan varios de sus biógrafos ${ }^{203}$.

198 A las biografías citadas de Astrana, Canavaggio, Alvar, pueden añadirse Mckendrick, Melveena, Cervantes, Barcelona, Salvat, 1986; BASCO PAScuAL, Javier, Miguel de Cervantes Saavedra. Regocijo de las musas, Valladolid, Universidad, 2005. Sobre Cervantes en Valladolid: ORTEGA y Rubio, J., Cervantes en Valladolid, Valladolid, 1888. Pérez Mínguez, F., La casa de Cervantes en Valladolid, Madrid, 1905. Alonso CoRTÉS, Narciso, Cervantes en Valladolid, Valladolid, Casa de Cervantes, 1918.

199 Canavaggio, Jean, Op. cit., pp. 172-175.

${ }^{200}$ Ibidem, p. 175.

201 Ibidem, p. 183.

20220 Documentos sobre Cervantes, (...), ed. Carlos Baztán, transcripción Beatriz Moñino, prólogo J. J. Allen, Madrid, Comunidad, 2001, pp. 44 y ss.

${ }^{203}$ Como se habrá comprobado no trato de vida y sociedad en el Quijote por lo que no tomo en cuenta valerosos estudios como los de Castro, Osterc, Salomón, Márquez Villanueva, Maravall, Redondo, Salazar, etc. 